\title{
Componentes da biomassa e características estruturais em capim-aruana sob diferentes frequências e intensidades de desfolhação
}

\author{
Leane Veras da Silva(1), Magno José Duarte Cândido(1), João Paulo Matos Pessoa(1), \\ Ana Clara Rodrigues Cavalcante ${ }^{(2)}$, Maria Socorro de Souza Carneiro ${ }^{(1)}$ e Antônio do Nascimento Silva ${ }^{(1)}$
}

(1)Universidade Federal do Ceará, Departamento de Zootecnia. Avenida Mister Hull, no 2.977, Campus do Pici, CEP 60440-554 Fortaleza, CE, Brasil. E-mail: leaneveras@zootecnista.com.br, magno@ufc.br, jpmatospessoa@gmail.com, msocorro@ufc.br, nascimento_silva@live.com (2)Embrapa Caprinos e Ovinos, Estrada Sobral-Groaíras, Km 4, Caixa Postal 145, CEP 62010-970 Sobral, CE, Brasil. E-mail: ana.clara@embrapa.br

Resumo - O objetivo deste trabalho foi avaliar o efeito de frequências e intensidades de desfolhação sobre os componentes da biomassa e a estrutura do dossel em capim-aruana (Panicum maximum 'Aruana IZ-5'), pastejado sob lotação rotativa com ovinos. Avaliaram-se duas frequências de desfolhação (FD), com níveis de interceptação de 85 e $95 \%$ da radiação fotossinteticamente ativa (Irfa) incidente no topo do dossel, e duas intensidades de desfolhação (ID), com índices de área foliar residual (IAFr) de 1,0 e 1,8. Utilizou-se o delineamento inteiramente casualizado, com arranjo fatorial $2 \times 2$. Os componentes da biomassa e as características estruturais nas condições de pré-pastejo foram afetados principalmente pela FD, com a redução da biomassa de colmos verdes e de forragem morta, e, ainda, pela elevação da altura da primeira lígula viva. Pastos manejados com menor FD proporcionaram menor relação lâmina foliar/colmo, com média de 1,65, e os pastos com maior FD apresentaram média de lâmina foliar/colmo de 2,40. Os componentes da biomassa residual foram afetados pela ID, com maior biomassa de forragem verde residual em pastos manejados com IAFr de 1,8. Os pastos manejados com 95\% de Irfa e IAFr de 1,8 apresentaram biomassa de colmo verde residual e biomassa de forragem morta residual superiores aos dos demais manejos. Para pastejo por ovinos, o capim-aruana deve ser manejado com frequência de $85 \%$ de Irfa e intensidade de desfolhação correspondente a IAFr de 1,0.

Termos para indexação: Panicum maximum, altura do dossel, índice de área foliar residual, intercepção da radiação fotossinteticamente ativa.

\section{Biomass components and structural features in Guinea grass under different frequencies and intensities of defoliation}

\begin{abstract}
The objective of this work was to evaluate the effect of frequencies and intensities of defoliation on the biomass components and on the canopy structure of Guinea grass (Panicum maximum 'Aruana IZ-5') pasture under intermittent sheep stocking. Two defoliation frequencies (DF), with 85 and $95 \%$ interception levels of the photosynthetically active radiation (Ipar) incident on the top of the canopy, and two defoliation intensities (DI), with residual leaf area index (LAIr) of 1.0 and 1.8 were evaluated. A completely randomized design was carried out, in a $2 \times 2$ factorial arrangement. Biomass components and the structural features in the pre-grazing conditions were affected mainly by DF, with the reduction of green biomass of culms and of dead forage, and were also affected by the increase in the height of the first alive ligule. Pastures managed with lower DF provided lower leaf blade/culm ratio, with 1.65 average, while pastures managed with greater DF showed 2.40 mean leaf blade/culm ratio. Components of the residual biomass were affected by the DI, with a greater residual green forage biomass in pastures managed with LAIr of 1.8. Swards grazed at 95\% Ipar and 1.8 LAIr showed residual green biomass of culms and residual dead forage biomass superior to those of the other managements. For grazing by sheep, 'Aruana' Guinea grass should be managed with a $85 \%$ Ipar frequency and defoliation intensity corresponding to LAIr of 1.0.
\end{abstract}

Index terms: Panicum maximum, canopy height, residual leaf area index, interception of photosynthetically active radiation.

\section{Introdução}

O manejo inadequado dos pastos é um dos grandes responsáveis pela baixa produtividade da pecuária brasileira. Pastos com maior acúmulo em biomassa de colmos e de forragem morta são resultantes da má aplicação das técnicas de manejo, no que se refere principalmente à frequência e intensidade de desfolhação (Barbosa et al., 2007; Silva et al., 2007). 
Melhores respostas da maximização da taxa de acúmulo de forragem, especificamente de folhas, são obtidas quando se utilizam frequências de desfolhação equivalentes a $95 \%$ da RFA(radiação fotossinteticamente ativa) interceptada no topo do dossel. O momento ideal para a realização do corte ou pastejo, quando correlacionado a esta medida, pode evitar perdas de forragem e baixa eficiência de utilização de forragem (Cutrim Junior et al., 2011).

A interrupção do período de descanso, antes de os pastos atingirem $95 \%$ de interceptação da RFA, pode resultar em melhor valor nutritivo da forragem, maior facilidade de apreensão pelo animal (Barbosa et al., 2007; Zanine et al., 2011) e, posteriormente, melhor desempenho animal, principalmente pela maior oferta de biomassa de lâminas foliares verdes (Trindade et al., 2007). Contudo, a adoção desse manejo em pastejos sucessivos pode comprometer a capacidade de rebrotação da planta forrageira, diminuindo, assim, a disponibilidade de forragem. Em regiões com maior incidência de RFA, como o Nordeste brasileiro, é possível a frequência de desfolhação entre 85 a $95 \%$ da RFA interceptada pelo dossel (Cândido et al., 2006; Cutrim Junior et al., 2011).

$\mathrm{O}$ índice de área foliar residual (IAFr) representa a intensidade de desfolhação que influencia a rebrotação dos pastos. Quando o IAFr é mais elevado, a planta apresenta um período menor de dependência dos carboidratos de reserva, em consequência da melhor utilização da área foliar residual, o que proporciona maiores taxas de fotossíntese foliar (Pedreira et al., 2007).

O capim-aruana, por ser uma espécie de baixo porte e cujos meristemas estão posicionados mais próximos ao solo, pode ser manejado com IAFr menor sem afetar a persistência do pasto (Zanini et al., 2012). No entanto, estudos que contrastem IAFr maiores e menores são necessários, a fim de se conhecer melhor o comportamento dessa gramínea ainda pouco estudada.

O objetivo deste trabalho foi avaliar o efeito de frequências e intensidades de desfolhação sobre os componentes da biomassa e as características estruturais de Panicum maximum 'Aruana IZ-5', pastejado sob lotação rotativa por ovinos.

\section{Material e Métodos}

O experimento foi realizado no Campo Avançado do Núcleo de Ensino e Estudos em Forragicultura,
Fazenda Experimental Vale do Curu, pertencente ao Centro de Ciências Agrárias da Universidade Federal do Ceará, no município de Pentecoste, CE, a 351'18"S e 39 $18^{\prime} 13 \mathrm{~W}$. O clima, segundo a classificação de Köeppen, é do tipo BSw'h' - semiárido quente -, com precipitação média anual de $806,5 \mathrm{~mm}$ distribuída de janeiro a abril. A média anual de umidade relativa do ar é de 73,8\%. O solo é classificado como Neossolo Flúvico, solos aluviais (Santos et al., 2006). O período experimental transcorreu de outubro de 2013 a fevereiro de 2014.

Utilizou-se o delineamento experimental inteiramente casualizado em arranjo fatorial $2 \times 2$. Os tratamentos consistiram de combinações de duas frequências de desfolhação (FD): tempo para que o dossel interceptasse 85 e $95 \%$ da radiação fotossinteticamente ativa (RFA); e duas intensidades de desfolhação (ID), com índices de área foliar residual (IAFr) de 1,0 e 1,8, com cinco repetições.

O capim-aruana foi irrigado por aspersão de baixa pressão (pressão de serviço $<2,0 \mathrm{kgf} \mathrm{cm}^{-2}$ ) e submetido à adubação nitrogenada. Os pastos foram adubados com $560 \mathrm{~kg} \mathrm{ha}^{-1}$ de N por ano, conforme recomendação de Nogueira et al. (2011), para obtenção de máximo acúmulo de lâminas foliares e mínima senescência para esta gramínea, em que se utilizou a ureia como fonte de nitrogênio. A dose aplicada foi dividida pelo número de ciclos de pastejo possíveis ao longo de um ano, para os diferentes períodos de descanso. A estimativa inicial dos períodos de descanso, que foram posteriormente ajustados no decorrer do experimento, foi realizada conforme descrito em Cutrim Junior et al. (2011). A quantidade de ureia para a adubação nitrogenada correspondente a cada ciclo foi fracionada em duas aplicações: uma após a saída dos animais e outra aproximadamente na metade do período de descanso. A irrigação foi realizada durante a noite, para minimizar a perda de água, com turno de rega de quatro dias, e lâminas de irrigação de $7,9 \mathrm{~mm}$ por dia.

Vinte piquetes experimentais, com $190 \mathrm{~m}^{2}$ cada, foram utilizados para pastejo sob lotação rotativa, com média de quatro dias de ocupação e taxa de lotação variável. Como agentes de desfolhação utilizaram-se 35 ovinos Morada Nova, machos, inteiros, com peso inicial de 18,4 $\pm 1,0 \mathrm{~kg}$, com média de oito meses de idade. Cada piquete foi provido de saleiro, bebedouro e tela de sombreamento móvel $(75 \%$ de sombra e área de $8,0 \mathrm{~m}^{2}$ ). Os animais foram conduzidos aos 
piquetes, quando alcançados os níveis de interceptação preconizados, a fim de garantir o rebaixamento do dossel para o IAFr de 1,0 ou 1,8 .

Para garantir que os pastos haviam atingido as frequências de desfolhação esperadas e, também, ao fim do período de pastejo, realizaram-se as avaliações da interceptação de radiação fotossinteticamente ativa (Irfa) e índice de área foliar (IAF) do dossel, por meio do analisador PAR-LAI, modelo Accupar LP-80 (Decagon Devices, Inc., Pullman, Washington, DC, EUA). Determinaram-se os valores das frequências e das intensidades de desfolhação, por meio da diferença de interceptação da radiação. Efetuaram-se leituras de forma aleatória, uma acima e uma abaixo do dossel (ao nível do solo), no total de 14 leituras em cada piquete experimental. Realizaram-se também, nas condições pré e pós-pastejo, medições da altura do dossel $(\mathrm{cm})$, tendo-se amostrado aleatoriamente 30 pontos por piquete, com auxílio de bastão graduado retrátil, em que se mediu a distância do solo até a curvatura da folha mais alta tocada pela ponta do bastão. No mesmo perfilho, realizou-se a mensuração da altura da primeira lígula viva (APLV), a mais velha abaixo do dossel. A partir da diferença entre a AD e a APLV, foi possível determinar o horizonte de pastejo (HP). A densidade populacional de perfilhos (DPP) foi estimada a partir da contagem dos perfilhos em duas molduras de 0,25 $\mathrm{m}^{2}$ (Nogueira et al., 2011; Zanini et al., 2012), em cada repetição. Quando submetido a $95 \%$ de Irfa, o capim-aruana atinge $30 \mathrm{~cm}$ de altura; é uma gramínea cespitosa de porte baixo e dossel uniforme, o que justifica a utilização de molduras de menor área, mesmo para uma gramínea do gênero Panicum (Zanini et al., 2012).

Para as condições pré e pós-pastejo, a cada ciclo, em cada piquete experimental, a biomassa total, presente em duas molduras de área conhecida $\left(0,25 \mathrm{~m}^{2}\right)$, foi coletada e, em seguida, as amostras foram encaminhadas ao laboratório para pesagem e separação dos componentes: lâmina foliar, colmo (colmo verdadeiro + bainha) e material morto. As amostras foram secas em estufa de ventilação forçada $\left(55^{\circ} \mathrm{C}\right.$ até obtenção de massa constante), para estimativa das produções de biomassa de forragem nas condições pré e pós-pastejo.

$\mathrm{Na}$ condição pré-pastejo, avaliaram-se as seguintes variáveis de biomassa: de forragem total (BFT, $\mathrm{kg} \mathrm{ha}^{-1}$ por ciclo); forragem morta (BFM, $\mathrm{kg} \mathrm{ha}^{-1}$ por ciclo), forragem verde (BFV, $\mathrm{kg} \mathrm{ha}^{-1}$ por ciclo); lâmina foliar verde (BLV, $\mathrm{kg} \mathrm{ha}^{-1}$ por ciclo) e colmo verde (BCV, $\mathrm{kg} \mathrm{ha}^{-1}$ por ciclo). Determinaram-se as proporções lâmina foliar/colmo $(\mathrm{LF} / \mathrm{C})$ e material vivo/material morto (MV/MM).

Na condição pós-pastejo foram avaliadas as seguintes variáveis de biomassa: forragem total residual (BFTr, $\mathrm{kg} \mathrm{ha}^{-1}$ por ciclo); forragem morta residual (BFMr, $\mathrm{kg} \mathrm{ha}^{-1}$ por ciclo); de forragem verde residual (BFVr, $\mathrm{kg} \mathrm{ha}^{-1}$ por ciclo); lâmina foliar verde residual (BLVr, $\mathrm{kg} \mathrm{ha}^{-1}$ por ciclo); e de colmo verde residual $(\mathrm{BCVr}$, $\mathrm{kg} \mathrm{ha-1}$ por ciclo). Determinaram-se também as proporções lâmina foliar/colmo residual $(\mathrm{LF} / \mathrm{Cr})$ e material vivo/material morto residual (MV/MMr).

Foram obtidos os seguintes ciclos de pastejo e dados de manejo: cinco ciclos de pastejo, para o manejo com FD 85 e IAFr $1,8(85 \times 1,8)$, com média de 15 dias de período de descanso (PD); quatro ciclos de pastejo, para os pastos manejados com $85 \times 1,0$ (18 dias de PD); quatro ciclos de pastejo, para os pastos manejados com $95 \times 1,8$ (20 dias de PD); e três ciclos de pastejo, para os pastos manejados com 95x1,0 (24 dias de PD).

Os dados foram analisados em fatorial completo com a média de todos os ciclos e foram submetidos à análise de variância. As interações significativas pelo teste $\mathrm{F}$ foram desdobradas e comparadas pelo teste de Tukey, a 5\% de probabilidade. Como ferramenta auxiliar das análises estatísticas, utilizou-se o programa computacional SAS (SAS Institute, Cary, NC, EUA), tendo-se adotado o procedimento GLM para o efeito dos diferentes manejos.

\section{Resultados e Discussão}

Os ciclos de pastejo, obtidos com os referidos períodos de descanso, as respostas e as metas de manejo alcançadas encontram-se na Tabela 1.

Não houve interação entre os fatores avaliados (Tabela 2). Contudo, na condição pré-pastejo, houve efeito das FD sobre os seguintes componentes da biomassa: BFT, BFV, BLV, BCV, BFM e LF/C. Os pastos submetidos à $\mathrm{FD}$ a $85 \%$ de Irfa apresentaram menor produção de BFT, em relação aos pastos submetidos à FD a 95\% de Irfa. Um dos fatores que determina a produção de forragem é a quantidade de luz que é interceptada pelo dossel forrageiro. $\mathrm{O}$ aumento dos valores da BFT, com o aumento dos níveis de radiação interceptada pelo dossel, pode ser explicada pela maior eficiência de uso da RFA, o que ocasiona aceleração da taxa de crescimento, em 
condições ambientais favoráveis, até que o dossel intercepte $95 \%$ da luz incidente (IAF crítico), ponto em que a taxa média de acúmulo de forragem atinge seu máximo (Silva et al., 2009).

A maior produção de BFV, observada na menor FD, é resultante de produções mais altas de BCV e BLV. A produção de BLV, nos pastos submetidos a $95 \%$ de Irfa, foi maior do que em pastos manejados com $85 \%$ da Irfa. A BLV é uma variável de grande importância para o desempenho animal, pois é a fração mais selecionada no pastejo. Para alcançar os $95 \%$ de Irfa, os pastos submetidos à menor FD aumentam o número de folhas produzidas por perfilho, aumentando, assim, a capacidade de interceptar mais luz, o que irá resultar em maior massa de lâminas foliares, fato observado por Silva et al. (2007).

A BCV foi superior nos pastos manejados com 95\% de Irfa, em consequência do estiolamento ocasionado por uma redução da passagem de luz para a base dos perfilhos. A frequência com maior nível de interceptação não exerce efeito no controle de $\mathrm{BCV}$, no Nordeste brasileiro (Cutrim Junior et al., 2011), e proporciona perfilhos mais pesados e rígidos, tendo em vista o estádio mais avançado de crescimento (Marcelino et al., 2006). A FD a 85\% de Irfa exerceu efeito positivo no controle da $\mathrm{BCV}$ e proporcionou maior renovação de tecidos, tendo condicionado a estes dosséis perfilhos mais jovens e com menor contribuição de colmo verdadeiro (Marcelino et al., 2006; Silva et al., 2009).

A BFM aumentou à medida que aumentou a RFA interceptada pelo dossel. É provável que a senescência das folhas inferiores tenha sido antecipada, em consequência da redução da capacidade fotossintética ocasionada pelo sombreamento mútuo das folhas da porção superior do dossel (Cutrim Junior et al., 2014).

A LF/C diminuiu à medida que aumentou o percentual da RFA interceptada pelo dossel. De acordo com Pinto et al. (1994), tem-se admitido um limite crítico de 1,0 para esta relação, pois valores inferiores a este implicariam a queda da quantidade e qualidade da forragem produzida, o que limitaria o seu consumo pelos animais. $\mathrm{O}$ aumento da $\mathrm{BCV}$, verificado nos pastos manejados com menor FD foi determinante

Tabela 1. Respostas e metas de manejo, alcançadas em capim-aruana submetido a duas frequências de interceptação da radiação fotossinteticamente ativa (Irfa) e duas intensidades de desfolhação, com índice de área foliar residual (IAFr), ao longo dos ciclos de pastejo ${ }^{(1)}$.

\begin{tabular}{|c|c|c|c|c|c|c|c|c|}
\hline \multirow[t]{2}{*}{ Manejo (Irfa x IAFr) } & \multirow{2}{*}{$\begin{array}{c}\text { PD } \\
\text { (dias) }\end{array}$} & \multicolumn{5}{|c|}{ Ciclo de pastejo } & \multirow[t]{2}{*}{ Média } & \multirow{2}{*}{$\begin{array}{l}\text { CV } \\
(\%)\end{array}$} \\
\hline & & 1 & 2 & 3 & 4 & 5 & & \\
\hline & \multicolumn{8}{|c|}{ Índice de área foliar (IAF) } \\
\hline $85 \times 1,8$ & 15 & 3,15 & 3,34 & 3,33 & 3,32 & 3,52 & $3,33 \mathrm{~B}$ & 3,93 \\
\hline $85 \times 1,0$ & 18 & 3,31 & 3,44 & 3,57 & 3,46 & - & $3,45 \mathrm{~B}$ & 3,09 \\
\hline $95 \times 1,8$ & 21 & 4,73 & 4,87 & 4,71 & 4,92 & - & $4,81 \mathrm{~A}$ & 2,15 \\
\hline \multirow[t]{2}{*}{$\underline{95 \times 1,0}$} & 24 & 4,50 & 4,81 & 4,48 & - & - & $4,60 \mathrm{~A}$ & 4,03 \\
\hline & \multicolumn{8}{|c|}{ Interceptação da radiação fotossinteticamente ativa (Irfa) } \\
\hline $85 \times 1,8$ & 15 & 85,22 & 85,10 & 85,90 & 86,01 & 86,29 & $85,70 \mathrm{~B}$ & 0,60 \\
\hline $85 \times 1,0$ & 18 & 85,48 & 85,08 & 86,22 & 86,13 & - & $85,73 \mathrm{~B}$ & 0,63 \\
\hline $95 \times 1,8$ & 21 & 94,20 & 94,70 & 94,40 & - & - & $94,40 \mathrm{~A}$ & 0,27 \\
\hline \multirow[t]{2}{*}{$95 \times 1,0$} & 24 & 96,64 & 94,11 & 94,61 & - & - & $94,12 \mathrm{~A}$ & 0,52 \\
\hline & \multicolumn{7}{|c|}{ Índice de área foliar residual (IAFr) } & \\
\hline $85 \times 1,8$ & 15 & 1,81 & 1,78 & 1,73 & 1,71 & 1,69 & $1,74 \mathrm{~A}$ & 2,86 \\
\hline $85 \times 1,0$ & 18 & 1,00 & 1,04 & 1,04 & 1,03 & - & $1,03 \mathrm{~B}$ & 1,84 \\
\hline $95 \times 1,8$ & 21 & 1,79 & 1,71 & 1,79 & 1,69 & - & $1,75 \mathrm{~A}$ & 3,01 \\
\hline \multirow[t]{2}{*}{$95 \times 1,0$} & 24 & 0,98 & 1,06 & 0,99 & - & - & $1,01 \mathrm{~B}$ & 4,32 \\
\hline & \multicolumn{7}{|c|}{ Interceptação da radiação fotossinteticamente ativa, na condição residual (Irfar) } & \\
\hline $85 \times 1,8$ & 15 & 67,28 & 65,51 & 57,19 & 60,29 & 63,40 & $62,73 \mathrm{~A}$ & 6,45 \\
\hline $85 \times 1,0$ & 18 & 44,08 & 46,26 & 46,21 & 43,81 & - & $45,09 \mathrm{~B}$ & 2,94 \\
\hline $95 \times 1,8$ & 21 & 58,68 & 61,55 & 61,36 & 58,73 & - & $60,08 \mathrm{~A}$ & 2,65 \\
\hline $95 \times 1,0$ & 24 & 50,87 & 47,15 & 47,12 & - & - & $48,38 \mathrm{~B}$ & 4,46 \\
\hline
\end{tabular}

${ }^{(1)}$ Médias seguidas de letras iguais em cada variável, não diferem pelo teste de Tukey, a 5\% de probabilidade. IAF, índice de área foliar, na condição pré-pastejo; Irfa, interceptação da radiação fotossinteticamente ativa, na condição pré-pastejo; IAFr, índice de área foliar, na condição residual; Irfar, interceptação da radiação fotossinteticamente ativa, na condição residual; PD, período de descanso. 
para essa resposta. A LF/C é uma variável de grande importância para o manejo de plantas forrageiras em gramíneas tropicais (Gomide et al., 2007) e para a nutrição animal, pois está diretamente associada ao consumo e à facilidade com que os animais apreendem a forragem, em especial as folhas, fração preferida

Tabela 2. Componentes da biomassa de capim-aruana submetido a duas frequências de interceptação de radiação fotossinteticamente ativa (Irfa) e duas intensidades com índice de área foliar residual (IAFr) de desfolhação na condição pré-pastejo ${ }^{(1)}$.

\begin{tabular}{|c|c|c|c|c|c|}
\hline \multirow[t]{2}{*}{$\mathrm{IAFr}$} & \multicolumn{2}{|c|}{ Frequência de desfolhação } & \multirow[t]{2}{*}{ Média } & \multirow[t]{2}{*}{ Valor $\mathrm{p}$} & \multirow{2}{*}{$\begin{array}{l}\text { CV } \\
(\%)\end{array}$} \\
\hline & $85 \%$ & $95 \%$ & & & \\
\hline & \multicolumn{5}{|c|}{ Biomassa da forragem total (BFT, $\mathrm{kg} \mathrm{ha}^{-1}$ por ciclo) } \\
\hline 1,0 & 2.479 & 3.361 & 2.920 & \multirow{2}{*}{0,2415} & \multirow{2}{*}{14,59} \\
\hline 1,8 & 2.641 & 3.681 & 3.161 & & \\
\hline Média & $2.560 \mathrm{~b}$ & $3.521 \mathrm{a}$ & - & - & - \\
\hline \multirow[t]{2}{*}{ Valor $\mathrm{p}$} & \multicolumn{2}{|c|}{0,0002} & - & - & - \\
\hline & \multicolumn{5}{|c|}{ Biomassa de forragem verde (BFV, $\mathrm{kg} \mathrm{ha}^{-1}$ por ciclo) } \\
\hline 1,0 & 2.109 & 2.803 & 2.456 & \multirow{2}{*}{0,2578} & \multirow{2}{*}{13,17} \\
\hline 1,8 & 2.220 & 3.043 & 2.632 & & \\
\hline Média & $2.164 b$ & $2.923 \mathrm{a}$ & - & - & - \\
\hline \multirow[t]{2}{*}{ Valor $\mathrm{p}$} & \multicolumn{2}{|c|}{0,0001} & - & - & - \\
\hline & \multicolumn{5}{|c|}{ Biomassa de lâmina foliar verde ( $\mathrm{BLV}, \mathrm{kg} \mathrm{ha}^{-1}$ por ciclo) } \\
\hline 1,0 & 1.418 & 1.788 & 1.603 & \multirow{2}{*}{0,8245} & \multirow{2}{*}{10,51} \\
\hline 1,8 & 1.465 & 1.708 & 1.586 & & \\
\hline Média & $1.442 \mathrm{~b}$ & $1.748 \mathrm{a}$ & - & - & - \\
\hline \multirow[t]{2}{*}{ Valor $\mathrm{p}$} & \multicolumn{2}{|c|}{0,0009} & - & - & - \\
\hline & \multicolumn{5}{|c|}{ Biomassa de colmo verde (BCV, $\mathrm{kg} \mathrm{ha}^{-1}$ por ciclo) } \\
\hline 1,0 & 691 & 1015 & 853 & \multirow{2}{*}{0,0773} & \multirow{2}{*}{24,05} \\
\hline$\underline{1,8}$ & 755 & 1335 & 1045 & & \\
\hline Média & $723 b$ & $1175 \mathrm{a}$ & - & - & - \\
\hline \multirow[t]{2}{*}{ Valor $\mathrm{p}$} & \multicolumn{2}{|c|}{0,0004} & - & - & - \\
\hline & \multicolumn{5}{|c|}{ Biomassa de forragem morta (BFM, $\mathrm{kg} \mathrm{ha}^{-1}$ por ciclo) } \\
\hline 1,0 & 398 & 558 & 478 & \multirow{2}{*}{0,3597} & \multirow{2}{*}{25,93} \\
\hline 1,8 & 421 & 638 & 530 & & \\
\hline Média & $409 \mathrm{~b}$ & $598 \mathrm{a}$ & - & - & - \\
\hline Valor $\mathrm{p}$ & & & - & - & - \\
\hline & Rela & laterial vive & naterial & rto (MV/I & \\
\hline 1,0 & 6,44 & 5,76 & 6,10 & 03715 & 032 \\
\hline 1,8 & 6,04 & 5,40 & 5,72 & נוד, & (3,JL \\
\hline Média & 6,24 & 5,58 & - & - & - \\
\hline Valor $\mathrm{p}$ & & & - & - & - \\
\hline & & ação lâmin & oliar/col & $(\mathrm{LF} / \mathrm{C})$ & \\
\hline 1,0 & 2,48 & 1,81 & 2,14 & 0.1825 & 23.59 \\
\hline 1,8 & 2,32 & 1,49 & 1,90 & & \\
\hline Média & $2,40 \mathrm{a}$ & $1,65 b$ & - & - & - \\
\hline Valor $\mathrm{p}$ & & & - & - & - \\
\hline
\end{tabular}

(1)Médias seguidas de letras distintas, minúsculas nas linhas e maiúsculas nas colunas, diferem pelo teste Tukey, a $5 \%$ de probabilidade. por eles em virtude do maior valor nutritivo (Palhano et al., 2007).

A altura de dossel (AD) foi influenciada pelas FD (Tabela 3). À medida que se aumentou a interceptação, a $\mathrm{AD}$ na condição pré-pastejo também aumentou. Quando o Irfa chegou a $85 \%$, os pastos atingiram $20,7 \mathrm{~cm}$ de $\mathrm{AD}$, e quando Irfa se elevou a $95 \%$, os pastos atingiram 28,6 cm de AD. Para a entrada dos animais no pasto, a $\mathrm{AD}$ é um dos critérios a ser utilizado, pois é de fácil manejo e alta praticidade. Zanini et al. (2012) obtiveram altura de $30 \mathrm{~cm}$ em capim-aruana manejado a $95 \%$ de Irfa, valor bem próximo ao encontrado no presente trabalho. O controle do pastejo por meio da altura é uma forma prática de manejo, mas não pode ser utilizado isoladamente, e sim, associado a outras características fisiológicas e morfológicas, em decorrência do estiolamento em gramíneas tropicais (Cutrim Junior et al., 2011). O estiolamento é uma característica indesejável, pois reduz o valor nutricional do pasto e, portanto, não reflete com perfeição a participação dos componentes da BFT (BLV, BCV e BFM) e a qualidade do pasto ofertada para o animal.

Com a diminuição da FD, a APLV aumentou significativamente. A elevação da APLV contribui para a redução do HP e evidencia ainda mais o estiolamento em pastos manejados com $95 \%$ de Irfa, o que ocasiona a elevação do meristema apical, de forma que a emergência das novas folhas, neste manejo, ocorre em maior nível de inserção. A menor frequência associada à baixa ID proporcionou a elevação da APLV, o que contribuiu para a redução do HP. A APLV foi maior neste manejo em razão do estiolamento ocasionado pela redução da passagem de RFA no interior do dossel, o que causou um incremento da BCV.

Houve efeito das FD no HP (Tabela 3). Com o aumento da interceptação da RFA pelo dossel, o HP foi maior por sua relação com a AD. A maior amplitude do $\mathrm{HP}$, nos pastos manejados com $95 \%$ da Irfa, proporciona dificuldades de acesso pelos animais, os quais poderão enfrentar maior dificuldade na apreensão e ingestão de forragem, em razão da maior presença de colmo. Assim, cerca de $30 \%$ da BCV está contida no HP do capim-aruana manejado com $95 \%$ da Irfa (Zanini et al., 2012). A presença de colmos, bainha e material morto no HP limita a profundidade do bocado, e é frequente observar-se aumento do tempo por bocado, redução da taxa de bocados e aumento do tempo diário de pastejo (Carvalho et al., 2009; Difante et al., 2009). $\mathrm{O} \mathrm{HP}$ não deve ser superior à metade da $\mathrm{AD}$ (Zanini 
et al., 2012). Contudo, a redução da amplitude do horizonte de pastejo limita a participação de BCV e maximiza a $\mathrm{LF} / \mathrm{C}$, proporcionando melhores condições para a apreensão de forragem pelo animal em pastejo (Difante et al., 2009).

Não houve interação entre os fatores avaliados. Porém, os componentes da biomassa e a LF/Cr, na condição pós-pastejo, foram afetados pelas ID (Tabela 4). Esses resultados já eram esperados, em razão da maior quantidade de forragem remanescente do pastejo, nos pastos submetidos à menor ID empregada.

A maior ID, nos pastos com IAFr 1,0, determinou menor presença de lâminas foliares na condição residual. A maior presença de BLVr, nos pastos submetidos ao IAFr 1,8, permitiu estabelecer uma rebrotação mais rápida, que resultou em uma maior produção de fotoassimilados e diminuiu o tempo necessário para atingir o nível da RFA a ser interceptada pelo dossel. A BLVr tem um papel fundamental na

Tabela 3. Características estruturais em pasto de capim-aruana submetido a duas frequências de interceptação de radiação fotossinteticamente ativa (Irfa) e duas intensidades com índice de área foliar (IAFr) de desfolhação na condição pré-pastejo ${ }^{(1)}$.

\begin{tabular}{|c|c|c|c|c|c|}
\hline \multirow[t]{2}{*}{ IAFr } & \multicolumn{2}{|c|}{$\begin{array}{l}\text { Frequência de desfolhação } \\
\text { (percentagem de Irfa) }\end{array}$} & \multirow[t]{2}{*}{ Média } & \multirow[t]{2}{*}{ Valor $\mathrm{p}$} & \multirow[t]{2}{*}{$\begin{array}{l}\mathrm{CV} \\
(\%)\end{array}$} \\
\hline & $85 \%$ & $95 \%$ & & & \\
\hline & \multicolumn{5}{|c|}{ Densidade populacional de perfilhos (DPP, perfilhos $\mathrm{m}^{-2}$ ) } \\
\hline 1,0 & 1.916 & 1756 & 1.836 & \multirow{2}{*}{0,3445} & \multirow{2}{*}{5,95} \\
\hline 1,8 & 1.888 & 1.880 & 1.884 & & \\
\hline Média & 1.900 & 1.820 & - & - & - \\
\hline \multirow[t]{2}{*}{ Valor $\mathrm{p}$} & \multicolumn{2}{|c|}{0,1187} & - & - & - \\
\hline & \multicolumn{5}{|c|}{ Altura do dossel (AD, cm) } \\
\hline 1,0 & 20,9 & 28,1 & 24,5 & \multirow{2}{*}{0,3969} & \multirow{2}{*}{2,85} \\
\hline 1,8 & 20,5 & 29,0 & 24,8 & & \\
\hline Média & $20,7 \mathrm{~b}$ & $28,5 \mathrm{a}$ & - & - & - \\
\hline \multirow[t]{2}{*}{ Valor $\mathrm{p}$} & \multicolumn{2}{|c|}{0,0001} & - & - & - \\
\hline & \multicolumn{5}{|c|}{ Altura da lígula mais baixa (APLV, $\mathrm{cm})$} \\
\hline 1,0 & $6,7 \mathrm{Bb}$ & $7,7 \mathrm{Bb}$ & 7,2 & \multirow{2}{*}{0,0593} & \multirow{2}{*}{7,55} \\
\hline 1,8 & $6,3 \mathrm{Bb}$ & $9,0 \mathrm{Aa}$ & 7,7 & & \\
\hline Média & $6,5 \mathrm{~b}$ & $8,3 \mathrm{a}$ & - & - & - \\
\hline \multirow[t]{2}{*}{ Valor $\mathrm{p}$} & \multicolumn{2}{|c|}{0,0001} & - & - & - \\
\hline & \multicolumn{5}{|c|}{ Horizonte de pastejo (HP, cm) } \\
\hline 1,0 & 14,2 & 20,4 & 17,3 & \multirow{2}{*}{0,3857} & \multirow{2}{*}{3,46} \\
\hline 1,8 & 14,2 & 20,0 & 17,1 & & \\
\hline Média & $14,2 b$ & $20,2 \mathrm{a}$ & - & - & - \\
\hline Valor $\mathrm{p}$ & \multicolumn{2}{|c|}{0,0001} & - & - & - \\
\hline
\end{tabular}

${ }^{(1)}$ Médias seguidas de letras distintas, minúsculas nas linhas e maiúsculas nas colunas, diferem pelo teste Tukey, a 5\% de probabilidade. rebrotação do pasto, pois é diretamente proporcional à taxa de fotossíntese líquida do pasto (Gomide et al., 2002; Pedreira et al., 2007).

Os pastos manejados com IAFr 1,8 apresentaram $\mathrm{BCVr}$ e BFMr superiores aos manejados com IAFr 1,0. No pasto com IAFr 1,0, houve permanência de colmos

Tabela 4. Componentes da biomassa de capim-aruana submetido a duas frequências de interceptação da radiação fotossinteticamente ativa (Irfa) e duas intensidades com índice de área foliar residual (IAFr) de desfolhação na condição pós-pastejo ${ }^{(1)}$.

\begin{tabular}{|c|c|c|c|c|c|}
\hline \multirow[t]{2}{*}{ IAFr } & \multicolumn{2}{|c|}{$\begin{array}{l}\text { Frequência de desfolhação } \\
\text { (percentagem de Irfa) }\end{array}$} & \multirow[t]{2}{*}{ Média } & \multirow[t]{2}{*}{$\mathrm{p}$} & \multirow[t]{2}{*}{$\begin{array}{l}\text { CV } \\
(\%)\end{array}$} \\
\hline & $85 \%$ & $95 \%$ & & & \\
\hline & \multicolumn{5}{|c|}{ Biomassa da forragem total residual (BFTr, $\mathrm{kg} \mathrm{ha}^{-1}$ por ciclo) } \\
\hline 1,0 & 1.120 & 1.241 & $1.180 \mathrm{~B}$ & \multirow{2}{*}{0,0002} & \multirow{2}{*}{18,30} \\
\hline 1,8 & 1.648 & 1.863 & $1.756 \mathrm{~A}$ & & \\
\hline Média & 1.384 & 1.552 & - & - & - \\
\hline Valor $\mathrm{p}$ & \multicolumn{2}{|c|}{0,1779} & - & - & - \\
\hline & \multicolumn{5}{|c|}{ Biomassa de forragem verde residual (BFVr, $\mathrm{kg} \mathrm{ha}^{-1}$ por ciclo) } \\
\hline 1,0 & 835 & 839 & $837 \mathrm{~B}$ & \multirow{2}{*}{0,0001} & \multirow{2}{*}{18,78} \\
\hline 1,8 & 1.248 & 1.395 & $1.321 \mathrm{~A}$ & & \\
\hline Média & 1.042 & 1.117 & - & - & - \\
\hline Valor $\mathrm{p}$ & \multicolumn{2}{|c|}{0,4418} & - & - & - \\
\hline & \multicolumn{5}{|c|}{ Biomassa de lâmina foliar verde residual (BLVr, $\mathrm{kg} \mathrm{ha}^{-1}$ por ciclo) } \\
\hline 1,0 & 309 & 186 & 247B & \multirow{2}{*}{0,0001} & \multirow{2}{*}{19,55} \\
\hline 1,8 & 560 & 337 & $449 \mathrm{~A}$ & & \\
\hline Média & $435 \mathrm{a}$ & $305,4 \mathrm{~b}$ & - & - & - \\
\hline Valor $\mathrm{p}$ & \multicolumn{2}{|c|}{0,0019} & - & - & - \\
\hline & \multicolumn{5}{|c|}{ Biomassa de colmo verde residual (BCVr, $\mathrm{kg} \mathrm{ha}^{-1}$ por ciclo) } \\
\hline 1,0 & 526 & 654 & $590 \mathrm{~B}$ & \multirow{2}{*}{0,0005} & \multirow{2}{*}{16,85} \\
\hline 1,8 & 670 & 933 & $802 \mathrm{~A}$ & & \\
\hline Média & $598 \mathrm{~b}$ & $794 a$ & - & - & - \\
\hline Valor $\mathrm{p}$ & \multicolumn{2}{|c|}{0,0009} & - & - & - \\
\hline & \multicolumn{5}{|c|}{ Biomassa da forragem morta residual (BFMr, $\mathrm{kg} \mathrm{ha}^{-1}$ por ciclo) } \\
\hline 1,0 & 285 & 401 & 343B & \multirow{2}{*}{0,0024} & \multirow{2}{*}{17,84} \\
\hline 1,8 & 400 & 515 & $458 \mathrm{~A}$ & & \\
\hline Média & $342 b$ & $459 \mathrm{a}$ & - & - & - \\
\hline Valor $\mathrm{p}$ & \multicolumn{2}{|c|}{0,0022} & - & - & - \\
\hline & \multicolumn{5}{|c|}{ Relação material vivo/material morto residual (MV/MMr) } \\
\hline 1,0 & 3,42 & 2,24 & 2,83 & \multirow{2}{*}{0,1054} & \multirow{2}{*}{9,32} \\
\hline 1,8 & 3,35 & 2,71 & 3,03 & & \\
\hline Média & $3,38 \mathrm{a}$ & $2,47 b$ & - & - & - \\
\hline Valor $\mathrm{p}$ & & & - & - & - \\
\hline & & o lâmina fo & colmo re & al (LF/C & \\
\hline 1,0 & 0,59 & 0,32 & $0,45 \mathrm{~B}$ & 00095 & 2350 \\
\hline 1,8 & 0,86 & 0,37 & $0,61 \mathrm{~A}$ & 0,0095 & 23,59 \\
\hline Média & $0,73 a$ & $0,34 \mathrm{~b}$ & - & - & - \\
\hline Valor $\mathrm{p}$ & & & - & - & - \\
\hline
\end{tabular}

${ }^{(1)}$ Médias seguidas de letras distintas, minúsculas nas linhas e maiúsculas nas colunas, diferem pelo teste Tukey, a $5 \%$ de probabilidade. 
aproximadamente $26 \%$ menor do que no pasto com IAFr de 1,8. A menor FD resultou em elevação da quantidade de colmos e forragem morta (Tabela 4). A fração de colmos nos pastos manejados com IAFr de 1,0 foi controlada em razão da maior ID, pois os animais submetidos a esse manejo eram deixados na pastagem até que essa condição fosse alcançada. Essa circunstância forçava os animais a consumirem maior quantidade de colmos, o que é evidenciado pela diferença entre BCV (853 $\mathrm{kg} \mathrm{ha}^{-1}$ por ciclo) e BCVr (590 $\mathrm{kg} \mathrm{ha}^{-1}$ por ciclo), o que indica que houve consumo de $30 \%$ da BCV pelos animais.

A densidade populacional de perfilhos residual (DPPr) foi afetada apenas pela ID (Tabela 5). A DPPr nos pastos manejados com IAFr de 1,8 foi maior, pela ocorrência de perfilhamento aéreo, ocasionado pela maior BFTr, o que resultou em menor passagem de luz em quantidade e qualidade (maior relação vermelho:

Tabela 5. Características estruturais em pasto de capim-aruana submetido a duas frequências de interceptação da radiação fotossinteticamente ativa (Irfa) e duas intensidades com índice de área foliar residual (IAFr) de desfolhação na condição pós-pastejo ${ }^{(1)}$.

\begin{tabular}{|c|c|c|c|c|c|}
\hline \multirow[t]{2}{*}{ IAFr } & \multicolumn{2}{|c|}{$\begin{array}{l}\text { Frequência de desfolhação } \\
\text { (percentagem de Irfa) }\end{array}$} & \multirow[t]{2}{*}{ Média } & \multirow[t]{2}{*}{ Valor $\mathrm{p}$} & \multirow[t]{2}{*}{$\begin{array}{l}\mathrm{CV} \\
(\%)\end{array}$} \\
\hline & $85 \%$ & $95 \%$ & & & \\
\hline & \multicolumn{5}{|c|}{ Densidade populacional de perfilhos residual (DPPr, perfilhos $\mathrm{m}^{-2}$ ) } \\
\hline 1,0 & 1.588 & 1.568 & $1.576 \mathrm{~B}$ & \multirow{2}{*}{0,0297} & \multirow{2}{*}{11,02} \\
\hline 1,8 & 1.784 & 1.752 & $1.768 \mathrm{~A}$ & & \\
\hline Média & 1.688 & 1.660 & - & - & - \\
\hline \multirow[t]{2}{*}{ Valor $\mathrm{p}$} & \multicolumn{2}{|c|}{0,8749} & - & - & - \\
\hline & \multicolumn{5}{|c|}{ Altura do dossel residual (ADr, cm) } \\
\hline 1,0 & 12,7 & 12,8 & $12,7 \mathrm{~B}$ & \multirow{2}{*}{0,0001} & \multirow{2}{*}{5,53} \\
\hline 1,8 & 14,3 & 15,6 & $14,8 \mathrm{~A}$ & & \\
\hline Média & $13,3 \mathrm{~b}$ & $14,2 \mathrm{a}$ & - & - & - \\
\hline \multirow[t]{2}{*}{ Valor $\mathrm{p}$} & \multicolumn{2}{|c|}{0,0481} & - & - & - \\
\hline & \multicolumn{5}{|c|}{ Altura da lígula mais baixa residual (APLVr, $\mathrm{cm}$ ) } \\
\hline 1,0 & $6,4 \mathrm{Bb}$ & $7,0 \mathrm{Bb}$ & $6,7 \mathrm{~B}$ & \multirow{2}{*}{0,0034} & \multirow{2}{*}{5,83} \\
\hline 1,8 & $6,4 \mathrm{Bb}$ & $8,2 \mathrm{Aa}$ & $7,3 \mathrm{~A}$ & & \\
\hline Média & $6,4 b$ & $7,6 \mathrm{a}$ & - & - & - \\
\hline \multirow[t]{2}{*}{ Valor $\mathrm{p}$} & & & - & - & - \\
\hline & \multicolumn{5}{|c|}{ Horizonte de pastejo residual ( $\mathrm{HPr}, \mathrm{cm})$} \\
\hline 1,0 & 6,4 & 5,8 & $6,1 \mathrm{~B}$ & \multirow{2}{*}{0,0001} & \multirow{2}{*}{6,35} \\
\hline 1,8 & 7,7 & 7,2 & $7,5 \mathrm{~A}$ & & \\
\hline Média & $7,1 \mathrm{a}$ & $6,5 b$ & - & - & - \\
\hline Valor $\mathrm{p}$ & \multicolumn{2}{|c|}{0,0067} & - & - & - \\
\hline
\end{tabular}

${ }^{(1)}$ Médias seguidas de letras distintas, minúsculas nas linhas e maiúsculas nas colunas, diferem pelo teste Tukey, a $5 \%$ de probabilidade.

Pesq. agropec. bras., Brasília, v.50, n.12, p.1192-1200, dez. 2015

DOI: 10.1590/S0100-204X2015001200009 vermelho extremo) e influenciou positivamente a produção de perfilhos aéreos nesses pastos. Os pastos manejados com IAFr 1,0 apresentaram maior evolução da DPPr para a DPP, cujo acréscimo foi de 16,5\%. No entanto, nos pastos manejados com IAFr 1,8 houve pouca evolução da DPPr para a DDP $(6,5 \%)$. A baixa quantidade de luz incidente nas gemas basais, ocasionada pela maior BFTr, diminuiu a atividade de perfilhamento (Fialho et al., 2012). A DPPr e a DPP são variáveis de importante acompanhamento, pois permitem avaliar as condições de perenidade do pasto (Fialho et al., 2012).

A altura do dossel residual (ADr) foi afetada tanto pela FD como pela ID. As menores ID proporcionaram as maiores alturas residuais para os manejos $85 \times 1,8 \mathrm{e}$ $95 \times 1,8$ (Tabela 5).

Houve efeito dos fatores analisados apenas para as variáveis APLV (Tabela 3) e APLV residual (APLVr) (Tabela 5). O manejo 95x1,8 proporcionou maior APLV, em razão de sua menor FD e menor ID. Provavelmente, a maior presença de colmos e material morto não permitiu que os ovinos rebaixassem a vegetação, pois a presença desses componentes dificulta a acessibilidade a um HP mais profundo (Carvalho et al., 2009).

O horizonte de pastejo residual (HPr) foi afetado por ambos os fatores analisados. Os pastos manejados com $85 \times 1,8$ possibilitaram maior HPr. Esse resultado foi favorecido pela menor ID, em que se tinha um pasto mais alto na condição residual, associado à alta FD, em que os animais pastejavam principalmente as pontas das folhas e, em um curto período de descanso, o pasto já estava pronto para a desfolhação subsequente.

\section{Conclusões}

1. O capim-aruana (Panicum maximum) manejado à frequência de $85 \%$ de interceptação da radiação fotossinteticamente ativa apresenta menor biomassa de colmos e de forragem morta e maior relação lâmina foliar/colmo.

2. O capim-aruana pastejado por ovinos, no Nordeste brasileiro, deve ser manejado com frequência de desfolhação correspondendo a $85 \%$ de interceptação da radiação fotossinteticamente ativa e e intensidade de desfolhação correspondendo a um índice de área foliar residual de 1,0, que equivalem nesse estudo a uma altura média de entrada e saída de 20,7 e $12,7 \mathrm{~cm}$, respectivamente. 


\section{Agradecimentos}

Ao Conselho Nacional de Desenvolvimento Científico e Tecnológico (CNPq), pelo financiamento da pesquisa e concessão da bolsa de estudos; ao Núcleo de Ensino e Estudos em Forragicultura, pela cessão de sua estrutura física e equipamentos.

\section{Referências}

BARBOSA, R.A.; NASCIMENTO JÚNIOR, D. do; EUCLIDES, V.P.B.; SILVA, S.C. da; ZIMMER, A.H.; TORRES JUNIOR, R.A. de A. Capim-tanzânia submetido a combinações entre intensidade e frequência de pastejo. Pesquisa Agropecuária Brasileira, v.42, p.329-340, 2007. DOI: 10.1590/S0100-204X2007000300005.

CÂNDIDO, M.J.D.; SILVA, R.G. da; NEIVA, J.N.M.; FACÓ, O.; BENEVIDES, Y.I.; FARIAS, S.F. Fluxo de biomassa em capim-tanzânia pastejado por ovinos sob três períodos de descanso. Revista Brasileira de Zootecnia, v.35, p.2234-2242, 2006. DOI: 10.1590/S1516-35982006000800006.

CARVALHO, P.C. de F.; TRINDADE, J.K. da; MEZZALIRA, J.C.; POLI, C.H.E.C.; NABINGER, C.; GENRO, T.C.M.; GONDA, H.L. Do bocado ao pastoreio de precisão: compreendendo a interface planta animal para explorar a multi-funcionalidade das pastagens. Revista Brasileira de Zootecnia, v.38, p.109-122, 2009. DOI: $10.1590 /$ S1516-35982009001300013.

CUTRIM JUNIOR, J.A.A.; BEZERRA, A.P.A.; FARIAS, S.F.; AQUINO, R.M. da S.; SOMBRA, W.A.; ANDRADE, R.R. de; CÂNDIDO, M.J.D. Morfofisiologia do capim-tifton 85 manejado intensivamente sob corte. Acta Tecnológica, v.9, p.62-69, 2014.

CUTRIM JUNIOR, J.A.A.; CÂNDIDO, M.J.D.; VALENTE, B.S.M.; CARNEIRO, M.S. de S.; CARNEIRO, H.A.V. Características estruturais do dossel de capim-tanzânia submetido a três frequências de desfolhação e dois resíduos pós-pastejo. Revista Brasileira e Zootecnia, v.40, p.489-497, 2011. DOI: 10.1590/S1516-35982011000300005.

DIFANTE, G. dos S.; EUCLIDES, V.P.B.; NASCIMENTO JÚNIOR, D. do; SILVA, S.C. da; TORRES JÚNIOR, R.A. de A.; SARMENTO, D.O. de L. Ingestive behaviour, herbage intake and grazing efficiency of beef cattle steers on Tanzania guineagrass subjected to rotational stocking managements. Revista Brasileira de Zootecnia, v.38, p.1001-1008, 2009. DOI: 10.1590/ S1516-35982009000600005.

FIALHO, C.A.; SILVA, S.C. da; GIMENES, F.M. de A.; GOMES, M.B.; BERNDT, A.; GERDES, L. Tiller population density and tillering dynamics in marandu palisade grass subjected to strategies of rotational stocking management and nitrogen fertilization. Acta Scientiarum. Animal Sciences, v.34, p.137-139, 2012. DOI: 10.4025/actascianimsci.v34i3.13739.

GOMIDE, C.A. de M.; GOMIDE, J.A.; ALEXANDRINO, E. Características estruturais e produção de forragem em pastos de capim-mombaça submetidos a períodos de descanso. Pesquisa Agropecuária Brasileira, v.42, p.1487-1494, 2007. DOI: 10.1590/ S0100-204X2007001000017.
GOMIDE, C.A. de M.; GOMIDE, J.A.; HUAMAN, C.A.M. y; PACIULLO, D.S.C. Fotossíntese, reservas orgânicas e rebrota do capim-mombaça (Panicum maximum Jacq.) sob diferentes intensidades de desfolha do perfilho principal. Revista Brasileira de Zootecnia, v.31, p.2165-2175, 2002. DOI: 10.1590/ S1516-35982002000900003.

MARCELINO, K.R.A.; NASCIMENTO JUNIOR, D. do; SILVA, S.C. da; EUCLIDES, V.P.B.; FONSECA, D.M. da. Características morfogênicas e estruturais e produção de forragem do capim-marandu submetido a intensidades e frequências de desfolhação. Revista Brasileira de Zootecnia, v.35, p.2243-2252, 2006. DOI: 10.1590/S1516-35982006000800007.

NOGUEIRA, D.M.; MISTURA, C.; TURCO, S.H.N.; VOLTOLINI, T.V.; ARAÚJO, G.G.L. de; SOUZA, T.C. Aspectos clínicos, parasitológicos e produtivos de ovinos mantidos em pastagem de capim-aruana irrigado e adubado com diferentes doses de nitrogênio. Acta Scientiarum. Animal Sciences, v.33, p.175-181, 2011. DOI: 10.4025/actascianimsci.v33i2.9406.

PALHANO, A.L.; CARVALHO, P.C. de F.; DITTRICH, J.R.; MORAES, A. de; SILVA, S.C. da; MONTEIRO, A.L.G. Características do processo de ingestão de forragem por novilhas holandesas em pastagens de capim-mombaça. Revista Brasileira de Zootecnia, v.36, p.1014-1021, 2007. DOI: 10.1590/ S1516-35982007000500005.

PEDREIRA, B.C. e; PEDREIRA, C.G.S.; SILVA, S.C. da. Estrutura do dossel e acúmulo de forragem de Brachiaria brizantha cultivar Xaraés em resposta a estratégias de pastejo. Pesquisa Agropecuária Brasileira, v.42, p.281-287, 2007. DOI: 10.1590/ S0100-204X2007000200018.

PINTO, J.C.; GOMIDE, J.A.; MAESTRI, M. Produção de matéria seca e relação folha: caule de gramíneas forrageiras tropicais, cultivadas em vasos, com duas doses de nitrogênio. Revista da Sociedade Brasileira de Zootecnia, v.23, p.313-326, 1994.

SANTOS, H.G. dos; JACOMINE, P.K.T.; ANJOS, L.H.C. dos; OLIVEIRA, V.A. de; OLIVEIRA, J.B. de; COELHO, M.R.; LUMBRERAS, J.F.; CUNHA, T.J.F. (Ed.). Sistema brasileiro de classificação de solos. 2.ed. Rio de Janeiro: Embrapa Solos, 2006. $306 \mathrm{p}$.

SILVA, S.C. da; BUENO, A.A. de O.; CARNEVALLI, R.A.; UEBELE, M.C.; BUENO, F.O.; HODGSON, J.; MATTHEW, C.; ARNOLD, G.C.; MORAIS, J.P.G. de. Sward structural characteristics and herbage accumulation of Panicum maximum cv. Mombaça subjected to rotational stocking managements. Scientia Agricola, v.66, p.8-19, 2009. DOI: 10.1590/ S0103-90162009000100002.

SILVA, R.G. da; CÂNDIDO, M.J.D.; NEIVA, J.N.M.; LÔBO, R.N.B.; SILVA, D.S. da. Características estruturais do dossel de pastagens de capim-tanzânia mantidas sob três períodos de descanso com ovinos. Revista Brasileira de Zootecnia, v.36, p.1255-1265, 2007. DOI: 10.1590/ S1516-35982007000600006.

TRINDADE, J.K. da; SILVA, S.C. da; SOUZA JÚNIOR, S.J. de; GIACOMINI, A.A.; ZEFERINO, C.V.; GUARDA, V.D.A.; CARVALHO, P.C. de F. Composição morfológica da forragem consumida por bovinos de corte durante o rebaixamento do 
capim-marandu submetido a estratégias de pastejo rotativo. Pesquisa Agropecuária Brasileira, v.42, p.883-890, 2007. DOI: 10.1590/S0100-204X2007000600016.

ZANINE, A. de M.; NASCIMENTO JÚNIOR, D. do; SANTOS, M.E.R.; PENA, K. da S.; SILVA, S.C. da; SBRISSIA, A.F. Características estruturais e acúmulo de forragem em capim-tanzânia sob pastejo rotativo. Revista Brasileira de Zootecnia, v.40, p.2364-2373, 2011. DOI: 10.1590/ S1516-35982011001100012.

ZANINI, G.D.; SANTOS, G.T.; SCHMITT, D.; PADILHA, D.S.; SBRISSIA, A.F. Distribuição de colmo na estrutura vertical de pastos de capim-Aruana e azevém anual submetidos a pastejo intermitente por ovinos. Ciência Rural, v.42, p.882-887, 2012. DOI: $10.1590 / \mathrm{S} 0103-84782012000500020$.

Recebido em 9 de março de 2015 e aprovado em 22 de outubro de 2015 